\title{
S-allylcysteine Improves Streptozotocin-Induced Alterations of Blood Glucose, Liver Cytochrome P450 2E1, Plasma Antioxidant System, and Adi- pocytes Hormones in Diabetic Rats
}

\author{
Ganapathy Saravanan ", , Ponnusamy Ponmurugan ${ }^{2}$ \\ ${ }^{1}$ Department of Biochemistry, Centre for Biological science, K.S.Rangasamy College of Arts and Science, Thokkavadi, Tiruchengode,Tamil Nadu, India \\ 2 Department of Biotechnology, K.S.Rangasamy College of Technology, Thokkavadi, Tiruchengode, Tamil Nadu, India \\ ${ }^{*}$ Corresponding author: Ganapathy Saravanan, Research Department of Biochemistry, Centre for Biological Science, K. S. Rangasamy College of Arts and Science, Thokkavadi, Ti- \\ ruchengode, Tamil Nadu, 637215, India. Tel: +91-9843954422, E-mail: saravana_bioc@rediffmail.com.
}

Received: February 24, 2013; Revised: March 09, 2013; Accepted: March 17, 2013

\begin{abstract}
Background: S-allylcysteine, a garlic derivative, could have a protective effect against pathogenesis of diabetes mellitus.
Objectives: Sustained free radical generation and oxidative damage to system leads to the final conclusion phase of diabetes and also it coexists with a constant diminution in the antioxidant status.The present study aims to evaluate the therapeutic effects of S-allylcysteine (SAC) against adipocytes hormones and antioxidant defense systems of plasma and erythrocytes of treptozotocin (STZ) induced diabetes in rats.

Materials and Methods: Diabetic rats were administered SAC ( $150 \mathrm{mg} / \mathrm{kg}$ b.w) orally for 45 days. At $46^{\text {th }}$ day, the rats were anesthetized, and blood and liver sample were collected for analyzing glucose, plasma insulin, CYP2E1 activity, Thiobarbituric acid reactive substances (TBARS), hydroperoxide, enzymatic and nonenzymatic antioxidants, reduced glutathione (GSH), ceruloplasmin, plasma leptin, and adiponectin.

Results: The levels of glucose, CYP2E1 activity, Thiobarbituric acid reactive substances (TBARS), hydroperoxide, and ceruloplasmin were increased significantly; whereas, the levels of plasma insulin, reduced glutathione, enzymatic and nonenzymatic antioxidants, leptin and adiponectin were decreased in experimental diabetic rats. Administration of SAC to diabetic rats led to a decrease in the levels of glucose, CYP2E1 activity, TBARS, and ceruloplasmin. In addition, the levels of plasma insulin, enzymatic and nonenzymatic antioxidants leptin and adiponectin were increased in SAC treated diabetic rats. Gliclazide, a standard drug for diabetes, was used for the comparative purpose. Conclusions: The results of the present investigation suggest that SAC could be used as a food supplement in the treatment of diabetes characterized by provoked antioxidant status, altered blood glucose, and hormones level.
\end{abstract}

Keywords: Antioxidants; Diabetes; Lipid Peroxidation; S- allylcysteine

\section{Background}

Diabetic mellitus (DM) is a chronic metabolic disorder characterized by hyperglycemia which affects all the metabolic pathways (1). It is a systemic disease with relentless metabolic imbalances and pathological alterations in many tissues and premature mortality, costing for at least $10 \%$ of total healthcare expenses in many countries (2). The present number of diabetics across the world exceeds 150 million, which has been predicted to rise to $>300$ million by the year 2025 (2), and it might be due to an increase in sedentary lifestyle, consumption of energy rich diet, and obesity (3). The occurrence of diabetes in urbanized countries is rapidly increasing, and this pandemic disease is one of the most persistent causes of death in developed countries. According to recent studies in India, the number of diabetics wouldbe 84-224 million by the year 2025 and the most prevalence wouldbe among urban population (4).
Oxidative stress, the occurrence of oxidant factors plays a key role in the development of diabetes and its complications (5). Persistent hyperglycemia can enhance the oxidative stress by increasing glucose auto-oxidation, nonenzymatic protein glycation, and activation of polyol pathway (6). It is suggested that the rise in free radical activity may play an imperative role in lipid peroxidation and protein oxidation of cellular structures which are the main causes of morbidity and mortality in diabetes. In recent years, there has been increased interest in oxygen-reactive species generation and its role in the development of complications of diabetes. Recently, a growing concern has brought back to traditional and alternative medicines which replace the synthetic one. Results of the previous report had clearly stated that apart from traditional antidiabetic treatment, antioxidant therapy would be beneficial in diabetes (7).

Cytochrome P450 2E1 (CYP2E1), a source of reactive oxy-

Implication for health policy/practice/research/medical education:

In this study, it was cleared that S-allylcysteine possesses antidiabetic and antioxidant properties. This study clearly suggests that, S-allylcysteine may be used as a dietary supplement which actsas neutraceutical.

Copyright @ 2013 , Research Institute For Endocrine Sciences and Iran Endocrine Society; Published by Kowsar. This is an Open Access article distributed under the terms of the Creative Commons Attribution License (http://creativecommons.org/licenses/by/3.0), which permits unrestricted use, distribution, and reproduction in any medium, provided the original work is properly cited. 
gen species (ROS), metabolizes different endogenous compounds, viz, fatty acids, lipid hydroperoxides, and ketone bodies (8). Ann et al. (9) reported that CYP2E1 is involved in the etiology and pathology of many diseases including diabetes (9). Previous report has shown that the expression of CYP2E1 messenger (m) RNA and protein is increased during diabetes (8). An increased CYP2E1 expression in various tissues of STZ-induced diabetic rats including the liver has been reported recently (10).During diabetes, the elevated CYP2E1 level may be an important risk factor for oxidative stress (9).

Persistent hyperglycemia is always associated with increased oxidative stress (7). During the course of diabetes, autoxidation of glucose and declined antioxidant enzymes system seem to be relevant to the elevated oxidative stress (11). Recent reports indicated that leptin and adiponectin were negatively modulated by oxidative stress $(12,13)$.

Recently, plant based treatment has been thought to be effective for the prevention and control of various diseases including diabetes (14). Garlic (Allium sativum, Liliaceae) is a rich source of bioactive compounds and is used in folk medicine for the treatment of various diseases. S-allylcysteine (SAC) a garlic derivative has been reported to have diverse potential including antioxidant activity (15), anticancer (16), antihepatotoxic (17), and neutrotrophic activity (18). Data from our recent study clearly reported the therapeutic potential of SAC against hyperglycemic status in diabetic rats (19). SAC also reverses the alterations in carbohydrate metabolizing enzymes (20), and glycoprotein metabolism (21).

\section{Objectives}

The present study was investigated to evaluate the therapeutic effect of SAC and gliclazide on oxidative stress induced by hyperglycemia, which enhances the modulations in erythrocytes and adipocytes hormones of STZ induced diabetic rats. The effects produced by SAC were compared with gliclazide.

\section{Materials and Methods}

\subsection{Animals}

Adult male albino rats of Wistar strain weighing around 150 to $180 \mathrm{~g}$ were used in this study. They were housed in polypropylene cages over husk bedding, and a 12 hour light and dark cycle was maintained throughout the experimental period. Rats were fed a commercial pellet diet and water ad libitum. The experiments were conducted according to the ethical norms approved by the Institutional Animal Ethics Committee guidelines.

\subsection{Chemicals}

SAC (99\%) was purchased from LGC Prochem, Bangalore, India.Streptozotocin and all other chemicals (acids, bases, solvents and salts) used were of analytical grade obtained from Himedia, Bangalore, India.

\subsection{Animal Treatment and Induction of Diabetes}

Type 1 diabetes was induced by the administration of STZ (55 mg/kg b.w, i.p). Blood glucose concentrations were measured at $72 \mathrm{~h}$ after injection of STZ. Rats with blood glucose level $>250 \mathrm{mg} / \mathrm{dl}$ were used in the present study. Diabetic rats were divided into 4 different groups, namely normal control rats, diabetic control rats, diabetic rats treated with SAC $150 \mathrm{mg} / \mathrm{kg}$ b.w, p.o. daily[20], and gliclazide $5 \mathrm{mg} / \mathrm{kg}$ b.w p.o. daily(22) for 45 days.

Blood was collected at different time interval $\left(10^{\text {th }}, 20^{\text {th }}\right.$, and $45^{\text {th }}$ days) by nicking the tip of tail under light ether anesthesia in clean dry tubes. It was used for the estimation of glucose. At the end of 45 days treatment, animals were fasted for 10 hours and killed by cervical decapitation. Blood samples were collected for the estimation of antioxidant parameters.

\subsection{Biochemical Assays}

\subsubsection{Determination of Blood Glucose, Plasma Leptin and Adiponectin}

Commercially available diagnostic kits (Sigma Diagnostics (I) Pvt. Ltd., Baroda, India) were used for the estimation of blood glucose, plasma leptin, and adiponectin.

\subsubsection{Preparation of Haemolysate}

For preparation of haemolysate, $2 \mathrm{~mL}$ of blood was taken, and erythrocytes were separated by centrifugation at $1000 \times \mathrm{g}$ for $10 \mathrm{~min}$ at $4^{\circ} \mathrm{C}$. The lysate was repeatedly washed with $10 \mathrm{mmol} / \mathrm{L}$ phosphate buffer saline (PBS), and adjusted to a hematocrit (HCT) of 5 or $10 \%$. An aliquot of $0.5 \mathrm{ml}$ washed red blood cells was lysed with $4.5 \mathrm{~mL}$ of ice cold distilled water to prepare haemolysate.

\subsubsection{Determination of Lipid Peroxidation}

TBARS were estimated by the method of Fraga et al. (23). $0.5 \mathrm{~mL}$ of plasma was treated with $2 \mathrm{ml}$ (1:1:1 ratio) TBA-TCA-HCl reagent (thiobarbituric acid, $0.37 \%, 0.25 \mathrm{~N}$ $\mathrm{HCl}, 15 \%$ Trichloroacetic acid) and placed for $15 \mathrm{~min}$ in a boiling water bath and cooled. The clear supernatant was measured against reference blank at $535 \mathrm{~nm}$, and the values were expressed as $\mathrm{mM} / \mathrm{dL}$.

The level of hydroperoxide was determined by the method of Jiang et al. (24). $1.8 \mathrm{~mL}$ of Fox reagent was mixed with $0.2 \mathrm{~mL}$ of plasma, and then incubated for 30 min at room temperature, then read at $560 \mathrm{~nm}$. The results were expressed as $\mathrm{mM} / \mathrm{dL}$.

\subsubsection{Determination of Vitamin $C$}

Vitamin C was estimated by the method of Omaye et al. (25). Reduced dehydroascorbic acid was treated with 2, 4-dinitrophenylhydrazine (DNPH) to form the derivatives bis- 2,4-dinitrophenylhydrazone which undergoes 
rearrangement to form a product with an absorption maximum at 520 nm.

\subsubsection{Determination of Vitamin $E$}

Vitamin E was estimated by the method of Desai (26). The lipid residue was mixed with ferric chloride, orthophosphoric acid, and bathophenanthroline reagents. Vitamin E reduces ferric ion to ferrous ions and forms a pink colored complex with bathophenanthroline orthophosphoric acid. Absorption due to the pink complex was measured at 536nm.

\subsubsection{Determination of Reduced Glutathione}

Reduced glutathione was measured according to the method of Beutler and Kelley (27) (1963). The supernatant reacted with 5, 5'-dithio-bis-2-nitrobenzoic acid (DTNB), and the yellow derivativewas measured $412 \mathrm{~nm}$.

\subsubsection{Determination of Ceruloplasmin}

Ceruloplasmin was estimated by the method of Ravin (28). Ceruloplasmin oxidized p-phenylenediamine to form a purple colored compound. $1.0 \mathrm{~mL}$ of sodium azide solution was added to $0.05 \mathrm{~mL}$ of plasma. Then $1.0 \mathrm{~mL}$ phenylenediamine was added, mixed well and kept in a water bath at $37^{\circ} \mathrm{C}$ for one hour.All the tubes were kept at $4^{\circ} \mathrm{C}$ for 30 minutes.The color developed was read at 540 $\mathrm{nm}$.

\subsubsection{Determination of Superoxide Dismutase}

Superoxide dismutase (SOD) activity was assayed by the method of Kakkar et al. (29). The method involves generation of superoxide radical and its detection by nitrite formation from hydroxylamine hydrochloride. The nitrite reacts with sulphanilic acid to produce a diazonium compound which subsequently reacts with naphthylamine to produce a red azo compound whose absorbance is measured at $543 \mathrm{~nm}$.

\subsubsection{Determination of Catalase}

Catalase levels were determined by the Aebi's modified colorimetric method (30). $0.1 \mathrm{~mL}$ of tissue lysate and 0.4
$\mathrm{mL}$ of hydrogen peroxidewere added to $0.9 \mathrm{~mL}$ of phosphate buffer. After 60 seconds $2.0 \mathrm{~mL}$ of dichromate-acetic acid mixture was added. The tubes were kept in boiling water bath for 10 minutes, and the color developed was read at $620 \mathrm{~nm}$.

\subsubsection{Determination of Glutathione Peroxidase}

GPx activity was measured using the Paglia and Valentine's method (31). $0.1 \mathrm{~mL}$ of sodium azide and $0.5 \mathrm{~mL}$ of sample were addedto $0.2 \mathrm{~mL}$ of tris buffer, $0.2 \mathrm{~mL}$ of EDTA. To this mixture, $0.2 \mathrm{~mL}$ glutathione followed by $0.1 \mathrm{~mL}$ hydrogen peroxide was added. The contents were mixed well and incubated at $37^{\circ} \mathrm{C}$ for 10 minutes along with a tube containing all the reagents except sample. After 10 minutes the reaction was arrested with the addition of $0.5 \mathrm{~mL}$ of $10 \% \mathrm{TCA}$, centrifuged and the supernatant was assayed for glutathione.

\subsubsection{Determination of CYP2E1 Activity}

Assay of CYP2E1 activity wasperformed based on Ahn et al. (9) with slight modification. Liver samples were homogenized $(1: 2, \mathrm{w} / \mathrm{v})$ using $0.2 \mathrm{M}$ phosphate buffer (pH 7.4) containing 2 mM EDTA. The pellets were then suspended in a $0.2 \mathrm{M}$ sucrose containing $1 \mathrm{mM}$ EDTA and stored at $-80^{\circ} \mathrm{C}$ for further use. The enzyme activity was measured using the microsomal fractions, and the values were expressed as nmol hydroxylated nitrophenol $/ \mathrm{min} /$ mg protein. The protein concentrations were estimated using folin phenol using bovine albumin solution as the standard.

\subsection{Statistical Analysis}

All the results were expressed as Mean \pm S. D. Data was statistically evaluated with SPSS $\mid 10.0$ software. Hypothesis testing methods included one way analysis of variance (ANOVA) followed by least significant difference (LSD) test, $\mathrm{P}<0.05$ was considered to indicate statistical significance.

\section{Results}

Table 1 and Figure 1 showed the level of blood glucose,

Table 1. Effects of S-allylcysteine of Garlic on Blood Glucose Level at Different Intervals in Control and Experimental Diabetic Rats

\begin{tabular}{|c|c|c|c|c|}
\hline Rat Groups & Initial, mg/dL & $10^{\text {th }}$ day, mg/dL & $\mathbf{2 0}^{\text {th }}$ day, mg/dL & $45^{\text {th }}$ day, mg/dL \\
\hline Control & $95.6 \pm 3.1$ & $78.1 \pm 3.6$ & $105.6 \pm 10.4$ & $84.0 \pm 16.1$ \\
\hline Diabetic control & $275.3 \pm 10.9^{a, b}$ & $376.0 \pm 31.7^{a, b}$ & $430.8 \pm 84.0^{a, b}$ & $461.1 \pm 28.0^{a, b}$ \\
\hline $\begin{array}{l}\text { Diabetic }+ \text { S-allylcysteine }(150 \mathrm{mg} / \mathrm{kg} \text { body } \\
\text { weight) }\end{array}$ & $268.3 \pm 9.5^{\mathrm{a}, \mathrm{c}}$ & $320.3 \pm 19.7^{\mathrm{a}, \mathrm{c}}$ & $205.5 \pm 9.6^{\mathrm{a}, \mathrm{c}}$ & $105.0 \pm 16.5^{a, c}$ \\
\hline $\begin{array}{l}\text { Diabetic + gliclazide ( } 5 \text { mg/ kg body- } \\
\text { weight) }\end{array}$ & $252.8 \pm 74.0^{\mathrm{a}, \mathrm{c}}$ & $296.2 \pm 13.7^{a, c}$ & $165.2 \pm 14.8^{\mathrm{a}, \mathrm{c}}$ & $103.7 \pm 10.8^{\mathrm{a}, \mathrm{c}}$ \\
\hline
\end{tabular}

\footnotetext{
a Values are mean $\pm S D, n=6,{ }^{*} \mathrm{P}<0.05$

$\mathrm{b}$ Significantly different from untreated control

${ }^{\mathrm{c}}$ Significantly different from diabetic control
} 
Figure 1. Effects of SAC and Gliclazide on Plasma Insulin, Leptin and Adiponectin(Values Are Mean $\pm S D, n=6$ )

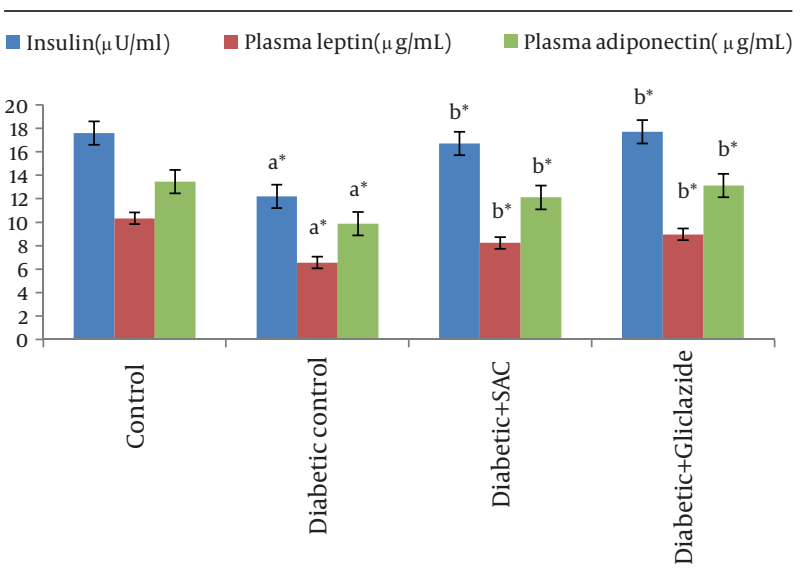

${ }^{\mathrm{a}}$ Group II compared with Group I

${ }^{\mathrm{b}}$ Group III and IV compared with Group II *P $<0.05$ plasma insulin, leptin and adiponectin in control and experimental animals.

The blood glucose was analyzed at different time intervals (10th, 20th and 45th day). The diabetic control rats showed a significant increase in the level of blood glucose with significant decrease in the level of plasma insulin, leptin and adiponectin. However, the level of blood glucose and plasma insulin, leptin and adiponectin werereturned to near normal concentrations in diabetic rats treated with SAC and gliclazide.

Table 2 summarized the concentration of TBARS and hydroperoxides in plasma and erythrocytes of control and experimental rats. The levels of TBARS and Hydroperoxides were significantly increased in diabetic animals compared to control animals. Oral treatment of SAC and gliclazide tended to bring plasma TBARS and hydroperoxides towards near normal levels.

Table 2. Effects of S-allylcysteine of Garlic on Thiobarbituric Acid Reactive Substances (TBARS) and Hydroperoxides in Plasma and Erythrocytes of Control and Experimental Diabetic Rats

\begin{tabular}{|c|c|c|c|}
\hline \multirow[t]{2}{*}{ Rat Groups } & \multicolumn{2}{|c|}{ TBARS, Mean $\pm S D(n=6)$} & \multirow{2}{*}{$\begin{array}{l}\text { Plasma Hydroperoxides, } \\
\mathrm{mM} / \mathrm{dL}, \text { Mean } \pm \operatorname{SD}(n=6)\end{array}$} \\
\hline & Plasma, nmol/mL & Erythrocytes, pM/mg Hb & \\
\hline Control & $3.42 \pm 0.54$ & $1.71 \pm 0.30$ & $1.98 \pm 0.92$ \\
\hline Diabetic control & $4.91 \pm 0.84^{\mathrm{a}}$ & $2.15 \pm 0.10^{\mathrm{a}}$ & $4.41 \pm 0.97^{\mathrm{a}}$ \\
\hline $\begin{array}{l}\text { Diabetic+ S-allylcysteine }(150 \mathrm{mg} / \mathrm{kg} \\
\text { body weight) }\end{array}$ & $3.06 \pm 0.79^{c}$ & $1.62 \pm 0.20^{C}$ & $2.87 \pm 0.21^{b}$ \\
\hline $\begin{array}{l}\text { Diabetic+gliclazide ( } 5 \mathrm{mg} / \mathrm{kg} \text { body } \\
\text { weight) }\end{array}$ & $2.59 \pm 0.54^{\mathrm{d}}$ & $1.69 \pm 0.10^{d}$ & $2.59 \pm 0.54^{\mathrm{d}}$ \\
\hline $\begin{array}{l}\mathrm{a}_{\text {Significantly different from control } \mathrm{P}<0.00} \\
\mathrm{~b}_{\text {Significantly different from diabetic control }} \\
\mathrm{c}_{\text {Significantly different from diabetic control }} \\
\mathrm{d}_{\text {Significantly different from diabetic control }}\end{array}$ & $\begin{array}{l}0.05 \\
0.01 \\
0.001\end{array}$ & & \\
\hline
\end{tabular}

Table 3. Effects of S-allylcysteine of Garlic on Nonenzymatic Antioxidants in the Plasma and Erythrocytes of Control and Experimental Diabetic Rats

\begin{tabular}{|c|c|c|c|c|}
\hline \multirow[t]{2}{*}{ Rat Groups } & \multicolumn{3}{|c|}{ Plasma, mg/Dl, Mean \pm S.D $(n=6)$} & \multirow{2}{*}{$\begin{array}{l}\text { Erythrocytes Reduced } \\
\text { Glutathione, } \mu \mathrm{mol} / \mathrm{g} \\
\text { Hb, Mean } \pm \text { S.D }(\mathbf{n}=\mathbf{6})\end{array}$} \\
\hline & Vitamin C & Vitamin E & Reduced Glutathione & \\
\hline Control & $5.53 \pm 1.03$ & $3.61 \pm 0.51$ & $29.33 \pm 2.63$ & $39.68 \pm 2.67$ \\
\hline Diabetic control & $3.07 \pm 0.97^{\mathrm{a}, \mathrm{b}}$ & $1.91 \pm 1.38^{\mathrm{a}}$ & $20.14 \pm 1.11^{\mathrm{a}, \mathrm{b}}$ & $27.36 \pm 0.81^{\mathrm{a}, \mathrm{b}}$ \\
\hline $\begin{array}{l}\text { Diabetic + S-allylcysteine (150mg/ } \\
\text { kg body weight) }\end{array}$ & $4.81 \pm 0.60^{c}$ & $3.01 \pm 0.59$ & $25.95 \pm 3.07^{\mathrm{C}}$ & $36.62 \pm 3.26^{\mathrm{d}}$ \\
\hline $\begin{array}{l}\text { Diabetic }+ \text { gliclazide }(5 \mathrm{mg} / \mathrm{kg} \text { body } \\
\text { weight) }\end{array}$ & $5.12 \pm 0.32^{C}$ & $3.55 \pm 0.96^{\mathrm{e}}$ & $26.81 \pm 2.17^{\mathrm{d}}$ & $38.7 \pm 2.11^{\mathrm{d}}$ \\
\hline $\begin{array}{l}\mathrm{a} \text { Significantly different from control }{ }^{*} \mathrm{P}<0 \text {. } \\
\mathrm{b} \text { Significantly different from control } \mathrm{P}<0.0 \\
\mathrm{c}^{\mathrm{c}} \text { Significantly different from diabetic contr. } \\
\mathrm{d}_{\text {Significantly different from diabetic contr }} \\
\mathrm{e}_{\text {Significantly different from diabetic contr }}\end{array}$ & $\begin{array}{l}P<0.01 \\
P<0.001 \\
P<0.05\end{array}$ & & & \\
\hline
\end{tabular}


of control and experimental rats. There was a significant decrease in the level of vitamin C, vitamin E and GSH in plasma of diabetic rats. Administration of SAC and gliclazide tended to bring the levels of nonenzymatic antioxidants towards near normal levels.

Table 4 exemplified the activities of SOD, CAT, GPx and ceruloplasmin in diabetic and control rats. There was a significant decrease in the activity of SOD, CAT and GPx and concomitant increasein the level of ceruloplasmin in diabetic rats when compared to control rats. Oral administration of SAC and gliclazide normalized the levels of enzymatic antioxidants towards normal.

Table 4. Effects of S- Allylcysteine of Garlic on Superoxide Dismutase (SOD), Catalase (CAT), Glutathione Peroxidase (GPx) and Ceruloplasmin in Control and Experimental Diabetic Rats

\begin{tabular}{|c|c|c|c|c|}
\hline Rat Groups $^{\mathrm{a}}$ & SOD, $\mathrm{U}^{\mathrm{a}} / \mathbf{m g ~ H b}$ & CAT, $\mathbf{U}^{\mathrm{b}} / \mathbf{m g}$ Hb & GPx, U⿱丷$/ \mathbf{m g ~ H b}$ & Ceruloplasmin, $\mathrm{mg} / \mathrm{dL}$ \\
\hline Control & $7.26 \pm 0.58$ & $133.4 \pm 6.04$ & $14.85 \pm 2.22$ & $23.2 \pm 3.16$ \\
\hline Diabetic control & $3.7 \pm 0.76^{b}$ & $90.68 \pm 1.88^{\mathrm{b}}$ & $9.68 \pm 0.59^{b}$ & $38.79 \pm 5.8^{b}$ \\
\hline $\begin{array}{l}\text { Diabetic + S-allylcysteine }(150 \mathrm{mg} / \mathrm{kg} \text { body } \\
\text { weight) }\end{array}$ & $5.07 \pm 0.53^{C}$ & $122.4 \pm 5.69^{\mathrm{e}}$ & $13.97 \pm 1.22^{\mathrm{d}}$ & $27.1 \pm 6.67^{\mathrm{d}}$ \\
\hline Diabetic + gliclazide $(5 \mathrm{mg} / \mathrm{kg}$ bodyweight $)$ & $5.48 \pm 0.85^{\mathrm{d}}$ & $127 \pm 8.9^{\mathrm{e}}$ & $14.31 \pm 1.94^{\mathrm{e}}$ & $26.65 \pm 5.49^{d}$ \\
\hline
\end{tabular}

$\mathrm{U}^{\mathrm{a}}$ The amount of enzyme required to inhibit $50 \%$ NBT reduction

$\mathrm{U}^{\mathrm{b}}$ Micromoles of $\mathrm{H} 2 \mathrm{O} 2$ utilized/min

$\mathrm{U}^{\mathrm{C}} \mu$ mole of glutathione oxidized per min per mg of protein

a Values are mean $\pm S D, n \pm 6$

b Significantly different from control $\mathrm{P}<0.001$

C Significantly different from diabetic control $\mathrm{P}<0.05$

d Significantly different from diabetic control $\mathrm{P}<0.01$

e Significantly different from diabetic control $\mathrm{P}<0.001$

CYP2E1-catalyzed p-nitrophenol hydroxylation activity in the liver of experimental and control rats were showed in Figure 2. Due to STZ intoxication, CYP2E1 activities increased in the liver of control and experimental group of rats. SAC administration to diabetic rats decreased the CYP2E1 activity near to normal.

Figure 2. Effects of SAC and Gliclazide Supplementation on CYP2E1 Activity in the Liver of Control and Experimental Groupsof Rats (Values Are Mean $\pm S D, n=6$ )

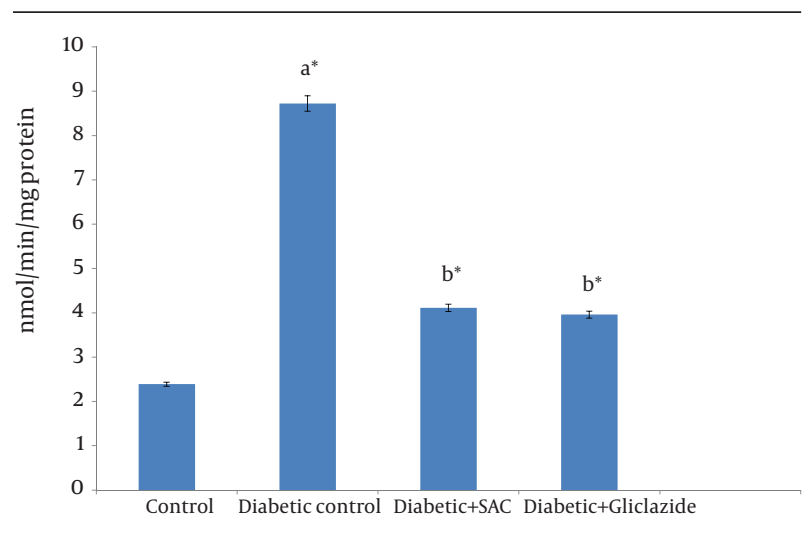

a Group II compared with Group I

b Group III and IV compared with Group II

${ }^{*} \mathrm{P}<0.05$

\section{Discussion}

Hyperglycemia induced by streptozocin in animals is considered to be a good model for the preface screening of drugs active against diabetes (32). ß-cells of pancreas are particularly liable to be damaged by STZ which leads to hyperglycemic condition (33). In the present investigation, the diabetic rats were found to have higher glucose levels and lower level of insulin when compared to normal control rats. From the results of the present experiment, it was observed that the daily administration of SAC during 45 days decreased the blood sugar in STZ induced diabetic rats. It is perhaps due to stimulation of insulin secretion from remnant pancreatic $\beta$-cells, which in turn enhances glucose utilization by peripheral tissues of diabetic rats either by promoting glucose uptake and metabolism, or by inhibiting hepatic gluconeogenesis (19).

Leptin and adiponectin, the chemical messengerssecreted by adipocytes, contribute to the regulation of lipid and glucose metabolism $(34,35)$. Leptin acts to reduce food intake and increase energy expenditure by activating specific hypothalamic receptors. Adiponectin improves insulin sensitivity by inspiring glucose uptake and fatty acid oxidation in skeletal muscle (36). In the present study, the plasma leptin and adiponectin levels were found to be lowered in the diabetic control rats compared tothe control rats. The results of our study are similar with the results of Thule et al. (37) and Kosova et al. (38) who found that plasma leptin and adiponectin were reduced in streptozocin-induced diabetic rats. In contrast to our results, some authors reported that plasma leptin and adiponectin were increased in patients with type 1 diabetes (39-41). The reasons for this discrepancy are not clear. From these results, the decreased level of plasma leptin and adiponectin levels in insulin-dependent diabetes mellitus may well be caused by an insulin deficiency and/or increased lipolysis. Oral administra- 
tion of SAC to diabetic rats led to an increase in Leptin and adiponectin levels. These observations suggest that the increased plasma leptin and adiponectin levels after SAC supplementation might be attributable to increased insulin level and decreased lipolysis (42).

TBARS assessment in plasma helps to assess the extent of tissue damage (43). In the present study, we found an increase in the levels of plasma hydroperoxide and TBARS which is a key factor of lipid peroxidation.The major pathological outcome of membrane lipid peroxidation by free radical induction includes increased membrane rigidity, decreased cellular deformability, reduced erythrocyte survival, and lipid fluidity $(44,45)$. Tremendous increase in lipid peroxidation observed in diabetic rats is attributed to constant hyperglycemia which causes increased production of reactive oxygen species (ROS). This may be due to the oxidation of monosaccharide (46) which causes tissue damage in membranes (47). Oral treatment with SAC prevented the increased level of lipid peroxidation markers, which could be as a result of improved glycemic control.

Vitamin C is a venerable water-soluble hydrophilic antioxidant which principally scavenges free radicals. It disappears faster than other antioxidants on exposure to reactive oxygen species (48). Vitamin C contributed up to $24 \%$ of the total peroxyl radical-trapping antioxidant activity (TRAP) (49). We have noted a decreased level of plasma vitamin $\mathrm{C}$ in the diabetic rats. This could be due to the increased consumption of vitamin $\mathrm{C}$ in the deactivation of the increased levels of reactive oxygen species or to the decreased GSH level, since the GSH is necessary for the recycling of vitamin C (50). Administration of SAC and gliclazide to diabetic rats tends to bring the Vitamin $\mathrm{C}$ to near normal levels, which could be as a result of increased GSH level.

Vitamin E, an imperative free radical scavenging chainbreaking antioxidant within biomembrane (51) interrupts the chain reactions of lipid peroxidation by reacting with lipid peroxyl radicals, thus defending the cell structures against damage (52). The amplified oxidative stress which accompanies a decrease in the level of antioxidants leads to decreased level of $\alpha$-tocopherol in diabetics (53). Treatment with SAC and gliclazide brought Vitamin E to near normal levels which could be as a result of decreased membrane damage.

Glutathione (GSH) is a metabolic regulator and putative indicator of health. GSH also functions as a free radical scavenger and in the repair of free radical caused biological damage (54). A marked depletion in the GSH content in plasma was observed in diabetic control rats. Reduced level of GSH in the circulation during diabetes represents its increased utilization due to oxidative stress (55). Hence, drugs that prevent the generation of these oxygen free radicals or increase the free radical scavenging enzymes may be effective in STZ induced diabetes. Furthermore, SAC treatment showed a significant renovation in GSH content of diabetic rats which may be due to the an- tioxidant property of SAC.

GPx plays a central role in the catabolism of $\mathrm{H} 2 \mathrm{O} 2$ and the detoxification of endogenous metabolic peroxides and hydroperoxides which catalyzes GSH (56). The decreased activity of GPx in this study might be due to the lowered level of GSH (57) in diabetic state. A marked increase in GPx was observed in diabetic rats treated with the SAC. This might reflect the antioxidant potency of SAC which reduced glucose levels and prevented glycation and inactivation of GPx. Thus GPx activity was induced to scavenge free radicals in diabetic rats.

Ceruloplasmin is a copper containing oxidase which inhibits lipid peroxidation by binding with the copper (58). During diabetes, the ceruloplasmin level is increased due to the generation of superoxide radicals and hydrogen peroxide (59). The level of ceruloplasmin was significantly increased in diabetic rats when compared to control rats which may facilitate the scavenging action on peroxyl radicals (60). Treatment with SAC prevented the increased level of ceruloplasmin compared to diabetic control. In SAC treated diabetic rats, low plasma ceruloplasmin levels might be due to an increase in their utilization to neutralize free radicals.

SOD, an essential defense enzyme catalyzed the dismutation of superoxide radicals (61). Due to hyperglycemia, the autoxidation of glucose results in the formation of hydrogen peroxide which inactivates SOD (62). Therefore, the accumulation of $\mathrm{H} 2 \mathrm{O} 2$ may be one of the explanations for decreased activity of SOD in diabetic condition. SOD is accountable for the detoxification of deleterious oxygen radicals (63). The observed decrease in SOD during diabetes could result from inactivation by $\mathrm{H} 2 \mathrm{O} 2$ or by glycation of the enzyme, which have been reported to occur in diabetes (64). In this study, the oral supplementation of SAC and gliclazide maintained the SOD activities at near control level. Namely, our results indicated that the preventive effects of SAC may be due to inhibition of lipid peroxidation and scavenging of free radicals by its antioxidant nature.

Catalase is a haem containing ubiquitous enzyme which removes toxic free radicals in vivo. CAT reduces $\mathrm{H} 2 \mathrm{O} 2$ produced by dismutation reaction and prevents generation of hydroxyl radicals (65). The present study revealed that CAT activities were significantly inhibited in erythrocytes of diabetic group which could be due to increased oxygen metabolites causing a decrease in the activity of the antioxidant defense system. Further, it was suggested that decreased antioxidant enzyme activity in DM is due to nonenzymatic glycosylation of the enzymes (66). Treatment with SAC and gliclazide has reversed the CAT activities, which could be as a result of decrease in the levels of lipid peroxidation and or decreasing utilization for scavenging free radicals.

STZ intoxication alkylates DNA and causes induction of CYP2E1 protein and mRNA (67). Incomplete reduction of oxygen due to leakage of electrons through the electron transport chain leads to the excessive production of ROS 
catalyzed by CYP2E1. The elevated ROS production, lipid peroxidation and the lowered antioxidant defense are common in diabetes (7). In the present study, increased liver CYP2E1 activity was observed in diabetic control rats. SAC supplementation leads to decreased blood glucose level and increased plasma insulin level in diabetic rats. Lower body glucose concentration ameliorated the induction of CYP2E1 and associated with liver injury (7).

In conclusion, the present study demonstrated that SAC administration significantly improved glycemic, antioxidant status and adipocytes hormones in diabetic rats by enhancing insulin. In conclusion, our result confirmed the antidiabetic action of SAC, and showed the favorable effect of SAC on erythrocyte antioxidants defense system and adipocytes hormones in addition to its antidiabetic effect.

\section{Acknowledgements}

The authors would like to thank the management of KSR College of Arts and Science, Tiruchengode, India, and Dr. N. Kannan, Principal of this college for their encouragement and also the management of Sastra University, Thanjavore, India for providing facilities to do animal studies.

\section{Authors' Contribution}

None declared.

\section{Financial Disclosure}

No conflicts of interest.

\section{Funding/Support}

None declared.

\section{References}

1. Chaiyasut C, Kusirisin W, Lailerd N, Lerttrakarnnon P, Suttajit M, Srichairatanakool S. Effects of phenolic compounds of fermented thai indigenous plants on oxidative stress in streptozotocin-induced diabetic rats. Evid Based Complement Alternat Med. 2011;2011:749307.

2. King H, Aubert RE, Herman WH. Global burden of diabetes, 19952025: prevalence, numerical estimates, and projections. Diabetes Care. 1998;21(9):1414-31.

3. Eidi A, Eidi M, Esmaeili E. Antidiabetic effect of garlic (Allium sativum L.) in normal and streptozotocin-induced diabetic rats. Phytomedicine. 2006;13(9-10):624-9.

4. Ramachandran A, Snehalatha C, Viswanathan Vijay. Burden of type 2 diabetes and its complications-The Indian scenario. Curr SCI-Banglore . 2002;83(12):1471-1476.

5. Baynes JW, Thorpe SR. Role of oxidative stress in diabetic complications: a new perspective on an old paradigm. Diabetes. 1999;48(1):1-9.

6. Pari L, Saravanan R. Beneficial effect of succinic acid monoethyl ester on erythrocyte membrane bound enzymes and antioxidant status in streptozotocin-nicotinamide induced type 2 diabetes. Chem Biol Interact. 2007;169(1):15-24.

7. Saravanan G, Ponmurugan P. Ameliorative potential of S-allyl cysteine on oxidative stress in STZ induced diabetic rats. Chem Biol Interact. 2011;189(1-2):100-6.

8. Woodcroft KJ, Hafner MS, Novak RF. Insulin signaling in the tran- scriptional and posttranscriptional regulation of CYP2E1 expression. Hepatology. 2002;35(2):263-73.

9. Ahn T, Yun $\mathrm{CH}$, Oh DB. Tissue-specific effect of ascorbic acid supplementation on the expression of cytochrome P450 2E1 and oxidative stress in streptozotocin-induced diabetic rats. Toxicol Lett. 2006;166(1):27-36.

10. Yao HT, Lin P, Chang YW, Chen CT, Chiang MT, Chang L, et al. Effect of taurine supplementation on cytochrome P450 2E1 and oxidative stress in the liver and kidneys of rats with streptozotocininduced diabetes. Food Chem Toxicol. 2009;47(7):1703-9.

11. Rosen P, Du X, Tschope D. Role of oxygen derived radicals for vascular dysfunction in the diabetic heart: prevention by alphatocopherol? Mol Cell Biochem. 1998;188(1-2):103-11.

12. Hattori Y, Akimoto K, Gross SS, Hattori S, Kasai K. Angiotensin-IIinduced oxidative stress elicits hypoadiponectinaemia in rats. Diabetologia. 2005;48(6):1066-74.

13. Jang SM, Kim MJ, Choi MS, Kwon EY, Lee MK. Inhibitory effects of ursolic acid on hepatic polyol pathway and glucose production in streptozotocin-induced diabetic mice. Metabolism. 2010;59(4):512-9.

14. Srivastava Y, Venkatakrishna-Bhatt H, Verma Y, Venkaiah K, Raval BH. Antidiabetic and adaptogenic properties of Momordica charantia extract: An experimental and clinical evaluation. Phytotherapy Research. 1993;7(4):285-289.

15. Herrera-Mundo MN, Silva-Adaya D, Maldonado PD, Galvan-Arzate S, Andres-Martinez L, Perez-De La Cruz V, et al. S-Allylcysteine prevents the rat from 3-nitropropionic acid-induced hyperactivity, early markers of oxidative stress and mitochondrial dysfunction. Neurosci Res. 2006;56(1):39-44.

16. Chu Q, Lee DT, Tsao SW, Wang X, Wong YC. S-allylcysteine, a watersoluble garlic derivative, suppresses the growth of a human androgen-independent prostate cancer xenograft, CWR22R, under in vivo conditions. BJU Int. 2007;99(4):925-32.

17. Nakagawat Shizutoshi, Kasuga Shigeo, Matsuura Hiromichi. Prevention of liver damage by aged garlic extract and its components in mice. Phytotherapy Research. 1989;3(2):50-53.

18. Moriguchi T, Matsuura H, Kodera Y, Itakura Y, Katsuki H, Saito H et al. Neurotrophic activity of organosulfur compounds having a thioallyl group on cultured rat hippocampal neurons. Neurochem Res.1997;22(12):1449-52.

19. Saravanan Ganapathy, Ponmurugan Ponnusamy, Kumar Gandhipuram Periasamy Senthil, Rajarajan Thatchinamoorthi. Antidiabetic properties of S-allyl cysteine, a garlic component on streptozotocin-induced diabetes in rats. J App Biomed. 2009;7:151-9.

20. Saravanan Ganapathy, Ponmurugan Ponnusamy, Senthilkumar Gandhipuram Periasamy, Rajarajan Thatchinamoorthi. Modulatory effect of S-allylcysteine on glucose metabolism in streptozotocin induced diabetic rats. Journal of Functional Foods. 2009;1(4):336-340.

21. Saravanan G, Ponmurugan P, Senthil Kumar GP, Rajarajan T. Antidiabetic effect of S-allylcysteine: Effect on plasma and tissue glycoproteins in experimental diabetes. Phytomedicine. 2010;17(14):1086-9.

22. Kaleem M, Asif M, Ahmed QU, Bano B. Antidiabetic and antioxidant activity of Annona squamosa extract in streptozotocin-induced diabetic rats. Singapore Med J. 2006;47(8):670-5.

23. Fraga CG, Leibouitz BE, Toppel AL. Free Radic. 'Lipid peroxidation measured as TBARS in tissue slic- es. Characterization and comparison with homogenate and microsomes. Free Rad Biol Med. 1988;4:155-161.

24. Jiang ZY, Hunt JV, Wolff SP. Ferrous ion oxidation in the presence of xylenol orange for detection of lipid hydroperoxide in low density lipoprotein. Anal Biochem. 1992;202(2):384-9.

25. Omaye ST, Turnbull JD, Sauberlich HE. Selected methods for the determination of ascorbic acid in animal cells, tissues, and fluids. Methods Enzymol.1979;62:3-11.

26. Desai ID. Vitamin E analysis methods for animal tissues. Methods Enzymol.1984;105:138-47.

27. Beutler E, Kelly Barbara M. The effect of sodium nitrite on red cell GSH. Experientia.1963;19(2):96-97.

28. Ravin HA. An improved colorimetric enzymatic assay of ceruloplasmin. J Lab Clin Med. 1961;58:161-8. 
29. Kakkar P, Das B, Viswanathan PN. A modified spectrophotometric assay of superoxide dismutase. Indian J Biochem Biophys. 1984;21(2):130-2.

30. Aebi H. Catalase in vitro. Methods Enzymol. 1984;105:121-6.

31. Paglia DE, Valentine WN. Studies on the quantitative and qualitative characterization of erythrocyte glutathione peroxidase. Lab Clin Med.1967;70(1):158-69.

32. Ivorra MD, Paya M, Villar A. A review of natural products and plants as potential antidiabetic drugs. J Ethnopharmacol. 1989;27(3):243-75.

33. Spinas GA. The Dual Role of Nitric Oxide in Islet beta-Cells. News Physiol Sci.1999;14:49-54

34. Garg MK, Dutta MK, Mahalle N. Adipokines (adiponectin and plasminogen activator inhhibitor-1) in metabolic syndrome. In dian J Endocrinol Metab. 2012;16(1):116-23.

35. Tsao TS, Lodish HF, Fruebis J. ACRP30, a new hormone controlling fat and glucose metabolism. Eur J Pharmacol. 2002;440(2-3):213-

36. Yamauchi T, Kamon J, Minokoshi Y, Ito Y, Waki H, Uchida S, et al. Adiponectin stimulates glucose utilization and fatty-acid oxidation by activating AMP-activated protein kinase. Nat Med. 2002;8(11):1288-95

37. Thule PM, Campbell AG, Kleinhenz DJ, Olson DE, Boutwell JJ, Sutliff RL, et al. Hepatic insulin gene therapy prevents deterioration of vascular function and improves adipocytokine profile in STZ diabetic rats. Am J Physiol Endocrinol Metab. 2006;290(1):E114-E122.

38. Kosova F, Sepici-Dincel A, Engin A, Memis L, Koca C, Altan N. The thyroid hormone mediated effects of insulin on serum leptin levels of diabetic rats. Endocrine. 2008;33(3):317-22.

39. Imagawa A, Funahashi T, Nakamura T, Moriwaki M, Tanaka S, Nishizawa $\mathrm{H}$, et al. Elevated serum concentration of adiposederived factor, adiponectin, in patients with type 1 diabetes. Diabetes Care. 2002;25(9):1665-6.

40. Mazaki-Tovi M, Feuermann Y, Segev G, Klement E, Yas-Natan E, Farkas A, et al. Increased serum leptin and insulin concentrations in canine hypothyroidism. Vet J. 2010;183(1):109-14.

41. Perseghin G, Lattuada G, Danna M, Sereni LP, Maffi P, De Cobelli $\mathrm{F}$, et al. Insulin resistance, intramyocellular lipid content, and plasma adiponectin in patients with type 1 diabetes. Am J Physio Endocrinol Metab. 2003;285(6):E1174-81.

42. Saravanan G, Ponmurugan P. Ameliorative potential of S-allylcysteine: effect on lipid profile and changes in tissue fatty acid composition in experimental diabetes. Exp Toxicol Pathol. 2012;64(6):639-44

43. Gutteridge JM. Lipid peroxidation and antioxidants as biomarkers of tissue damage. Clin Chem. 1995;41(12 Pt 2):1819-28.

44. Hunt JV, Smith CC, Wolff SP. Autoxidative glycosylation and possible involvement of peroxides and free radicals in LDL modification by glucose. Diabetes. 1990;39(11):1420-4

45. Kolanjiappan K, Manoharan S, Kayalvizhi M. Measurement of erythrocyte lipids, lipid peroxidation, antioxidants and osmotic fragility in cervical cancer patients. Clin Chim Acta. 2002;326(12):143-9.

46. Wolff SP, Dean RT. Glucose autoxidation and protein modification. The potential role of 'autoxidative glycosylation' in diabetes. Biochem J. 1987;245(1):243-50.

47. Das SSMNM, Vasisht S, Das N, Srivastava LM. Correlation between total antioxidant status and lipid peroxidation in hypercholesterolemia. Curr Sci-Banglore. 2000;78(4):486-486.

48. Wefers $\mathrm{H}$, Sies $\mathrm{H}$. The protection by ascorbate and glutathione against microsomal lipid peroxidation is dependent on vitamin E. Eur J Biochem. 1988;174(2):353-7.

49. Atanasiu RL, Stea D, Mateescu MA, Vergely C, Dalloz F, Briot F, et al. Direct evidence of caeruloplasmin antioxidant properties. Mol Cell Biochem.1998;189(1-2):127-35.

50. Chatterjee IB, Nandi A. Ascorbic acid: a scavenger of oxyradicals. Indian J Biochem Biophys. 1991;28(4):233-6.

51. Parks E, Traber MG. Mechanisms of vitamin E regulation: research over the past decade and focus on the future. Antioxid Redox Signal. 2000;2(3):405-12.

52. Takenaka Y, Miki M, Yasuda H, Mino M. The effect of alpha-tocopherol as an antioxidant on the oxidation of membrane protein thiols induced by free radicals generated in different sites. Arch Biochem Biophys. 1991;285(2):344-50.

53. Garg MC, Ojha S, Bansal DD. Antioxidant status of streptozotocin diabetic rats. Indian J Exp Biol. 1996;34(3):264-6.

54. Yoshida K, Hirokawa J, Tagami S, Kawakami Y, Urata Y, Kondo T. Weakened cellular scavenging activity against oxidative stress in diabetes mellitus: regulation of glutathione synthesis and efflux. Diabetologia. 1995;38(2):201-10.

55. Paolisso G, Di Maro G, Pizza G, D'Amore A, Sgambato S, Tesauro P, et al. Plasma GSH/GSSG affects glucose homeostasis in healthy subjects and non-insulin-dependent diabetics. Am J Physiol. 1992;263(3 Pt 1):E435-40.

56. Eaton JW. Catalase, glutathione peroxidase and hydrogen peroxidase. J Lab Clin Med. 1991;118:3-4.

57. Hodgson EK, Fridovich I. The interaction of bovine erythrocyte superoxide dismutase with hydrogen peroxide: inactivation of the enzyme. Biochemistry. 1975;14(24):5294-9.

58. Halliwell Barry, Gutteridge John MC. Free radicals in biology and medicine.: Oxford university press Oxford;1999.

59. Dormandy TL. Free-radical reaction in biological systems. Ann $R$ Coll Surg Engl. 1980;62(3):188-94.

60. Ravi K, Ramachandran B, Subramanian S. Effect of Eugenia Jambolana seed kernel on antioxidant defense system in streptozotocin-induced diabetes in rats. Life Sci. 2004;75(22):2717-31.

61. McCord JM, Keele BB, Jr, Fridovich I. An enzyme-based theory of obligate anaerobiosis: the physiological function of superoxide dismutase. Proc Natl Acad Sci U S A. 1971;68(5):1024-7.

62. Fajans SS. Diabetes mellitus, definition, classification, tests.; 1995.

63. Del Maestro RF. An approach to free radicals in medicine and biology. Acta Physiol Scand Suppl. 1980;492:153-68.

64. Dominguez C, Ruiz E, Gussinye M, Carrascosa A. Oxidative stress at onset and in early stages of type 1 diabetes in children and adolescents. Diabetes Care. 1998;21(10):1736-42.

65. Muruganandan S, Gupta S, Kataria M, Lal J, Gupta PK. Mangiferin protects the streptozotocin-induced oxidative damage to cardiac and renal tissues in rats. Toxicology. 2002;176(3):165-73.

66. Kennedy L, Baynes JW. Non-enzymatic glycosylation and the chronic complications of diabetes: an overview. Diabetologia. 1984;26(2):93-8.

67. Gonzalez FJ. The 2006 Bernard B. Brodie Award Lecture. Cyp2e1. Drug Metab Dispos. 2007;35(1):1-8. 